\title{
Osteoporosis Prevalence and Associated Factors in Patients With COPD: A Cross-Sectional Study
}

\author{
Denise Rossato Silva MD PhD, Ana Cláudia Coelho PT, Anelise Dumke PT, \\ Jorge Diego Valentini, Juliana Nunes de Nunes, Clarisse Luisa Stefani, \\ Lívia Fontes da Silva Mendes CNS, and Marli Maria Knorst MD PhD
}

\begin{abstract}
BACKGROUND: Osteoporosis is one of the systemic features of COPD. OBJECTIVE: To determine the prevalence of osteoporosis in a sample of COPD out-patients, and investigate the correlation between T-score (a comparison of the patient's bone mineral density to that of a healthy 30-year-old of the same sex and ethnicity) and several factors suggested to be associated with osteoporosis. METHODS: In a cross-sectional study, we conducted dual-energy X-ray absorptiometry bone mineral density scans of the hips and lumbar spine, and collected data on smoking and alcohol habits, menopausal status, comorbidities, inhaled and oral corticosteroid dose and duration of treatment, previous bone fractures, pulmonary function tests, calcium intake (via questionnaire on food frequency), vitamin D intake (via questionnaire on sunlight exposure), and physical activity (via the International Physical Activity Questionnaire). RESULTS: We evaluated 95 patients. Forty $(42 \%)$ were osteoporotic, $40(42 \%)$ were osteopenic, and $15(16 \%)$ had normal bone mass. We found significant bivariate correlations between femoral-neck $\mathrm{T}$-score and body mass index $(\mathrm{r}=\mathbf{0 . 5 5 1}$, $P<.001$ ), and femoral-neck T-score and International Physical Activity Questionnaire total activity score $(r=0.378, P<.001)$. There was a significant inverse relationship between femoral-neck T-score and BODE (body mass index, air-flow obstruction, dyspnea, and exercise capacity) index ( $r$ $=-0.246, P=.02)$. We also found significant correlations between $T$-score and $F_{E V}(r=0.251$, $P=.01)$, forced vital capacity $(\mathrm{r}=0.229, P=.03)$, percent-of-predicted functional residual capacity $(\mathrm{r}=-0.415, P<.001)$, inspiratory capacity $(\mathrm{r}=0.252, P=.01)$, ratio of inspiratory capacity to total lung capacity $(r=0.241, P=.02)$, and absolute and percent-of-predicted diffusing capacity of the lung for carbon monoxide $(r=0.366, P<.001$, and $r=0.338, P=.003$, respectively). CONCLUSIONS: We identified a high prevalence of osteoporosis and osteopenia in out-patients with COPD. Patients with osteoporosis had more severe COPD than patients with normal bone mass. Key words: bone loss; COPD; corticosteroids; osteopenia; osteoporosis. [Respir Care 2011;56(7): 961-968. (C) 2011 Daedalus Enterprises]
\end{abstract}

\section{Introduction}

COPD is among the most prevalent diseases and causes of death worldwide. It is characterized by chronic air flow

\footnotetext{
The authors are affiliated with the Department of Pulmonology, Hospital de Clínicas de Porto Alegre, Universidade Federal do Rio Grande do Sul, Porto Alegre, Rio Grande do Sul, Brazil.

This research was partly supported by the Fundo de Incentivo à Pesquisa e Eventos do Hospital de Clínicas de Porto Alegre, Brazil.
}

The authors have disclosed no conflicts of interest. limitation that is usually progressive. ${ }^{1}$ COPD can no longer be considered a disease restricted to the pulmonary tract. Recent data indicate that COPD is often associated with various systemic conditions, including systemic in-

Correspondence: Denise Rossato Silva MD PhD, Department of Pulmonology, Hospital de Clínicas de Porto Alegre, Rua Ramiro Barcelos, 2350 Largo Eduardo Zaccaro Faraco, Bairro Santa Cecília, Porto Alegre, Rio Grande do Sul, Brazil 90.035-903. E-mail: denise.rossato@ terra.com.br.

DOI: $10.4187 /$ respcare.01056 


\section{Osteoporosis Prevalence and Associated Factors in Patients With COPD}

flammation,,$^{2}$ and these extrapulmonary effects affect disease progression. ${ }^{3}$

Osteoporosis is one of the important systemic features of COPD. Osteoporosis is a systemic skeletal disease characterized by low bone mass and microarchitectural changes that increase bone-fracture risk. The World Health Organization defines osteoporosis as a bone density $\geq 2.5$ standard deviations below the bone density of a normal young adult. Osteopenia, a less severe form of bone loss, is defined as a bone density between 1 and 2.5 standard deviations below that reference point. ${ }^{4}$ The prevalence of osteoporosis in COPD patients is 2-fold to 5-fold higher than in age-matched subjects without air-flow obstruction., ${ }^{5,6}$ Osteopenia is present in 35-72\% of patients with COPD, and $36-60 \%$ of patients with COPD have been reported to be osteoporotic. . $^{-9}$

The underlying causes of osteoporosis in COPD remain unclear, but several factors significantly correspond to reduced bone density in COPD, including older age, female sex, and body mass index (BMI). However, the relationship to other factors, such as $\mathrm{FEV}_{1}$, tobacco smoking, physical inactivity, and corticosteroid therapy, are still controversial.9-11

We studied the prevalence of osteoporosis and osteopenia in a sample of COPD patients, and compared the clinical and functional characteristics of osteoporotic, osteopenic, and normal-bone-mass patients. We also studied the correlations between lumbar-spine T-score and femoral-neck T-score (T-score compares the patient's bone mineral density to that of a healthy 30-year-old of the same sex and ethnicity) and several factors that have been suggested to be associated with osteoporosis.

\section{Methods}

We conducted a cross-sectional survey in a general, tertiary-care, university-affiliated hospital with 750 beds, in Porto Alegre, Brazil. Our local ethics committee approved the study, and all subjects gave written informed consent. We sequentially enrolled patients with COPD from the hospital's out-patient clinics, from January 2008 to January 2009. The inclusion criteria were: clinically stable in the previous 4 weeks; and COPD confirmed by a ratio of $\mathrm{FEV}_{1}$ to forced vital capacity (FVC) of $<0.7$, measured 20 min after administration of albuterol. We classified COPD severity according to the Global Initiative for Chronic Obstructive Lung Disease (GOLD) criteria. ${ }^{12}$

After the medical visit, a pulmonologist from the research team interviewed the patient and collected the following data with a standardized questionnaire: smoking habits, alcohol intake, menopausal status, comorbidities, inhaled and oral corticosteroid dose and duration of treatment, long-term domiciliary oxygen therapy, and previous bone fractures. Alcohol consumption was calculated with the alcohol concentration of the most frequently consumed beverages in Brazil. ${ }^{13}$ Dose equivalences of inhaled corticosteroids were expressed as beclomethasone dipropionate equivalents.

In the week after the interview, we performed dualenergy X-ray absorptiometry bone mineral density scans of the hips (femoral neck) and lumbar spine. Osteopenia was defined as a T-score between -1.0 and -2.5 . Osteoporosis was defined as a T-score below -2.5 . T-scores higher than -1.0 were considered normal. ${ }^{14}$ Patients with an abnormal $\mathrm{T}$-score were referred to an endocrinologist, who excluded other causes of osteoporosis/osteopenia through clinical and laboratory assessment.

We performed pulmonary function tests (spirometry, plethysmography, and diffusing capacity of the lung for carbon monoxide $\left[\mathrm{D}_{\mathrm{LCO}}\right]$ ) with a computerized spirometer (MasterScreen PFT Pro, Erich Jaeger, Würzburg, Germany), according to the American Thoracic Society/European Respiratory Society guidelines, ${ }^{15-17}$ and with the reference values of Crapo et al. ${ }^{18-20}$ We report only the postbronchodilator values.

We measured dyspnea with the modified Medical Research Council dyspnea scale. ${ }^{21}$ We used the following BMI categories: low $<21 \mathrm{~kg} / \mathrm{m}^{2}$, normal $21-25 \mathrm{~kg} / \mathrm{m}^{2}$, overweight $25-30 \mathrm{~kg} / \mathrm{m}^{2}$, and obese $>30 \mathrm{~kg} / \mathrm{m}^{2}$. We calculated the BODE (body-mass index, air flow obstruction, dyspnea, and exercise capacity) index, as described previously. ${ }^{22}$ We performed arterial blood gas analysis and echocardiogram in some patients, when indicated $\left(\mathrm{S}_{\mathrm{pO}_{2}}<92 \%\right.$, and suspicion of pulmonary hypertension or cor pulmonale, respectively). We conducted the 6-minute walk test in a 27-m corridor, under the supervision of a trained nurse or physician, with biotelemetry, which allows precise and constant monitoring of heart rate and $\mathrm{S}_{\mathrm{pO}_{2}}$ throughout the test.

To assess calcium intake we used a food frequency questionnaire that is reproducible and validated. ${ }^{23,24}$ The list composition differs according to the study purpose, so we included mainly foods that are sources of calcium. The study's nutritionists reviewed the diet records and resolved any questions with the participant. We calculated the mean daily intake of calcium with version 1.5 of the NutWin Nutrition Support Program software (Health's Informatics Department, Escola Paulista de Medicina, Universidade Federal de São Paulo, São Paulo, Brazil).

Physical therapists from the research team assessed the participants' physical activity with the long version of the International Physical Activity Questionnaire (https:// sites.google.com/site/theipaq/home), which assesses the duration, frequency, and intensity of leisure, occupational, commuting, and household/yard activities in the past week. We used metabolic equivalent intensity values to estimate the levels of these activities. One metabolic equivalent 


\section{Osteoporosis Prevalence and Associated Factors in Patients With COPD}

intensity is defined as the energy spent sitting quietly $(4.184 \mathrm{~kJ} / \mathrm{kg} / \mathrm{h}) .{ }^{25}$

We performed vitamin D assessment with a sunlightexposure questionnaire that has questions on sunscreen use, skin phototype and color (Fitzpatrick classification scale $\left.{ }^{26}\right)$, time of day and duration of sun exposure in winter and summer months, location of residence (beach, mountain), open-air labor activities/jobs (eg, farming), and physical sun protections (use of hat, shirt, sunglasses). With each subject, the full assessment (questionnaires, examinations, and tests) was carried out in one week.

We estimated our required sample size from our literature review. $6,27,28 \mathrm{We}$ assumed an osteoporosis prevalence of $35 \%$ in COPD patients, so for a power of $80 \%$ and significance at $5 \%$, and assuming $10 \%$ of patients would be lost to follow-up, we calculated that 92 patients would be needed. To find a correlation (at least $r=0.30$ ) between bone mineral density and factors suggested to be associated with osteoporosis, with a power of $80 \%$ and significance at $5 \%$, we needed 85 patients. Data analysis was with statistics software (SPSS 14.0, SPSS, Chicago, Illinois). We performed one-way analysis of variance with a post hoc Tukey test or Kruskal Wallis test, and the Pearson (or the Spearman when indicated) correlation to evaluate relationships. We present the data as number of cases, mean $\pm \mathrm{SD}$, median and IQR, or odds ratio and 95\% CI, as appropriate. A 2 -sided $P$ value $<.05$ was considered significant in all analyses.

\section{Results}

One-hundred six patients met the inclusion criteria, and 11 refused to participate, so 95 were included in the analysis. There were no significant differences in sociodemographic characteristics between the patients who participated and those who refused to participate. Tables 1 and 2 show some of the characteristics of the study cohort. The cohort's mean age was $67.3 \pm 8.1$ years. Sixty-two (65\%) were male, and 55 (58\%) were white. The non-white participants were mostly black, brown, or mixed race. Mixed race Brazilians are mainly of mixed European, African, and Amerindian ancestry. Fifteen patients $(16 \%)$ had low BMI, 31 (33\%) had normal BMI, 31 (33\%) were overweight, and $18(19 \%)$ were obese (the percentages do not sum to $100 \%$ because of rounding). There were $1(1 \%), 21$ (22\%), 46 (48\%), and 27 (28\%) patients, respectively with GOLD stages I, II, III, and IV COPD. Ninety-one patients (96\%) were current or ex-smokers, and $10(11 \%)$ reported alcohol consumption in the past year (median intake $70 \mathrm{~g} /$ week, IQR 51-263 g/week). The most common comorbidities were systemic arterial hypertension (42 patients, $44 \%$ ), ischemic heart disease (14 patients, $15 \%$ ), and diabetes mellitus (10 patients, 11\%).
Table 1. Clinical and Demographic Characteristics $(n=95)$

\begin{tabular}{lc}
\hline \hline Age (y) & $67.3 \pm 8.1$ \\
White, no. (\%) & $55(58)$ \\
Male, no. (\%) & $62(65)$ \\
Height (m) & $1.61 \pm 0.09$ \\
Body mass index $\left(\mathrm{kg} / \mathrm{m}^{2}\right)$ & $25.8 \pm 4.7$ \\
Tobacco Use & \\
$\quad$ Current smoker, no. (\%) & $17(18)$ \\
$\quad$ Ex-smoker, no. (\%) & $74(78)$ \\
$\quad$ Never-smoker, no. (\%) & $4(4)$ \\
$\quad$ Pack years, median (IQR) & $49(21-74)$ \\
Alcohol consumption, no. (\%) & $10(11)$ \\
Menopausal or postmenopausal woman, no. (\%) & $31(94)$ \\
Inhaled corticosteroid user, no. (\%) & $65(68)$ \\
Oral corticosteroid user in the past year, no. (\%) & $34(36)$ \\
Daily calcium intake, median (IQR), mg & $723(457-1,038)$ \\
International Physical Activity Questionnaire total & $857(0-3,493)$ \\
$\quad$ activity, median (IQR), metabolic equivalent & \\
$\quad$ intensity min/week & \\
& \\
\hline values are mean \pm SD. & \\
\hline
\end{tabular}

Table 2. Pulmonary Function and Bone Density Results

\begin{tabular}{|c|c|}
\hline $\mathrm{FEV}_{1}(\%$ predicted $)$ & $41 \pm 16$ \\
\hline FVC (\% predicted $)$ & $67 \pm 18$ \\
\hline TLC (\% predicted) & $123 \pm 20$ \\
\hline $\mathrm{D}_{\mathrm{LCO}}(\%$ predicted $)$ & $43 \pm 17$ \\
\hline Dyspnea score, median (IQR)* & $3(1-4)$ \\
\hline 6-min walk distance $(\mathrm{m})$ & $386 \pm 115$ \\
\hline BODE index, median (IQR) & $4(3-6)$ \\
\hline $\mathrm{P}_{\mathrm{aO}_{2}}(\mathrm{~mm} \mathrm{Hg})$ & $73 \pm 15$ \\
\hline $\mathrm{P}_{\mathrm{aCO}_{2}}(\mathrm{~mm} \mathrm{Hg})$ & $41 \pm 6$ \\
\hline \multicolumn{2}{|l|}{ GOLD COPD stage, no. (\%) } \\
\hline I: $\mathrm{FEV}_{1} \geq 80 \%$ predicted & $1(1)$ \\
\hline II: $\mathrm{FEV}_{1} 50-80 \%$ predicted & $21(22)$ \\
\hline III: $\mathrm{FEV}_{1} 30-50 \%$ predicted & $46(48)$ \\
\hline $\begin{array}{l}\text { IV: } \mathrm{FEV}_{1}<30 \% \text { predicted, or } \mathrm{FEV}_{1} \\
\quad<50 \% \text { predicted plus chronic respirator } \\
\text { failure }\end{array}$ & $27(28) \dagger$ \\
\hline \multicolumn{2}{|l|}{ T-score, median (IQR) } \\
\hline Lumbar spine & $-2.30(-3.20$ to -1.20$)$ \\
\hline Femoral neck & $-1.60(-2.40$ to -1.00$)$ \\
\hline \multicolumn{2}{|c|}{ 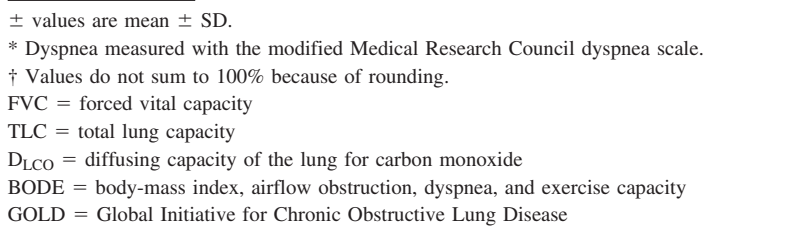 } \\
\hline
\end{tabular}

Sixty-five patients (68\%) were current users of inhaled corticosteroids (median and IQR dose 750, 750-1,000 $\mu \mathrm{g}$ beclomethasone equivalent, median and IQR duration of treatment 2, 1-5 y), and 34 (36\%) had been prescribed oral 
Table 3. Demographic and Clinical Characteristics Relative to Osteoporosis, Osteopenia, and Normal Bone Mass

\begin{tabular}{|c|c|c|c|c|}
\hline & $\begin{array}{l}\text { Osteoporosis } \\
\quad(n=40)\end{array}$ & $\begin{array}{l}\text { Osteopenia } \\
(n=40)\end{array}$ & $\begin{array}{l}\text { Normal Bone Mass } \\
\quad(n=15)\end{array}$ & $P$ \\
\hline Age (y) & $69.0 \pm 7.6$ & $66.6 \pm 8.4$ & $64.9 \pm 8.2$ & .18 \\
\hline Male, no. (\%) & $22(55)$ & $28(70)$ & $12(80)$ & .16 \\
\hline Smoking pack-years, median (IQR) & $40(20-61)$ & $49(25-68)$ & $64(44-98)$ & .13 \\
\hline White, no. (\%) & $19(58)^{*}$ & $26(90) \dagger$ & $10(91)^{* \dagger}$ & .006 \\
\hline Vertebral/hip fractures, no. (\%) & $9(23)^{*}$ & $1(3) \dagger$ & $1(7)^{* \dagger}$ & .02 \\
\hline Height (m) & $1.58 \pm 0.09 *$ & $1.61 \pm 0.68$ & $1.67 \pm 0.07 *$ & .004 \\
\hline Body mass index $\left(\mathrm{kg} / \mathrm{m}^{2}\right)$ & $24.8 \pm 5.1$ & $25.9 \pm 4.1$ & $27.9 \pm 4.8$ & .08 \\
\hline Alcohol consumption, no. (\%) & $5(13)$ & $9(23)$ & $5(33)$ & .20 \\
\hline \multicolumn{5}{|l|}{ Inhaled Corticosteroids } \\
\hline Used in the past year, no. (\%) & $27(68)$ & $26(65)$ & $12(80)$ & .56 \\
\hline Dose $(\mu \mathrm{g} / \mathrm{d})$ & $831 \pm 157$ & $884 \pm 463$ & $875 \pm 131$ & .82 \\
\hline Duration of use, median (IQR), y & $2(1-3)$ & $3(1-5)$ & $4(2-6)$ & .23 \\
\hline \multicolumn{5}{|l|}{ Oral Corticosteroids } \\
\hline Used in the past year, no. (\%) & $15(38)$ & $15(38)$ & $4(27)$ & .72 \\
\hline Dose $(\mathrm{mg} / \mathrm{d})$ & $29 \pm 13$ & $26 \pm 10$ & $30 \pm 14$ & .79 \\
\hline Duration of use, median (IQR), y & $5(5-9)$ & $5(5-9)$ & $7(5-7)$ & .90 \\
\hline Calcium intake, median (IQR), mg/d & $620(386-1,043)$ & $773(566-1132)$ & 694 (443-907) & .46 \\
\hline $\begin{array}{l}\text { International Physical Activity Questionnaire total activity, } \\
\text { median (IQR), metabolic equivalent intensity min/week }\end{array}$ & $720(0-2,520)$ & $560(25-3,548)$ & $1,104(136-17,000)$ & .24 \\
\hline $\begin{array}{l} \pm \text { values are mean } \pm \text { SD. } \\
* P \text { for the comparison between osteoporosis and normal bone mass. } \\
\dagger P \text { for the comparison between osteopenia and normal bone mass. }\end{array}$ & & & & \\
\hline
\end{tabular}

corticosteroids in the past year (20 [65\%] had received one prescription). Thirty-one (94\%) of the women were menopausal or postmenopausal, and $10(32 \%)$ were using hormone replacement therapy.

Of the 95 patients evaluated, $40(42 \%)$ were osteoporotic, $40(42 \%)$ were osteopenic, and $15(16 \%)$ had normal bone mass. There were no differences between the osteoporotic and non-osteoporotic groups in age, sex, smoking pack-years, alcohol consumption, or dose or duration of inhaled or oral corticosteroids (Table 3). Among the women patients with osteoporosis, osteopenia, and normal bone mass, respectively, $18 / 18(100 \%), 10 / 12(83 \%)$, and $3 / 3$ $(100 \%)$ were menopausal or postmenopausal $(P=.12)$.

Osteoporotic patients reported more vertebral and hip fractures than normal-bone-mass patients: 9 (23\%) vs $1(7 \%)(P=.02)$. The patients with normal bone mass were taller than the osteoporotic patients $(1.67 \pm 0.07 \mathrm{~m}$ vs $1.58 \pm 0.09 \mathrm{~m}, P=.004)$, and there were more white patients in the normal-bone-mass group than in the osteoporotic group: $10(91 \%)$ vs $19(58 \%)(P=.006)$. Patients with osteoporosis had a nonsignificantly lower BMI than patients with normal bone mass: $24.8 \pm 5.1 \mathrm{~kg} / \mathrm{m}^{2}$ vs $27.9 \pm 4.8 \mathrm{~kg} / \mathrm{m}^{2}(P=.08)$. A low BMI $\left(<21 \mathrm{~kg} / \mathrm{m}^{2}\right)$ was present in $1(7 \%), 5(13 \%)$, and $9(23 \%)$ patients with normal bone mineral density, osteopenia, and osteoporosis, respectively $(P=.27)$. A high BMI was present in 7 (47\%), 17 (43\%), and 7 (18\%) patients with normal bone mineral density, osteopenia, and osteoporosis, respectively
$(P=.03)$. Obesity was not different between the study groups: 4 (27\%) with normal bone mineral density, $6(15 \%)$ with osteopenia, and $8(20 \%)$ with osteoporosis $(P=.60)$.

The mean daily intake of calcium was not different between the osteoporotic, osteopenic, and normal-bonemass patients (see Table 3). Calcium intake was less than $1,200 \mathrm{mg}$ in 24 patients (82\%) with osteoporosis, 24 (77\%) with osteopenia, and 13 (93\%) with normal bone mass $(P=.45)$.

Eighty-seven patients (92\%) reported never using sunscreen. On average, the subjects reported being outside for a median and IQR $1,0.5-6.5 \mathrm{~h} / \mathrm{d}$ and used no sunscreen during winter, and for a median and IQR $1.5,0.88-5.5 \mathrm{~h} / \mathrm{d}$ during summer, and this was not different between the study groups $(P=.95$ and $P=.22$, respectively). There were no significant differences between the osteoporotic, osteopenic, and normal-bone-mass patients in skin phototype or color; location of residence (beach, mountain); open-air labor activities/jobs (eg, farming); or physical sun protection (use of hat, shirt, sunglasses).

Physical activity level was nonsignificantly higher in the patients with normal bone mass (median and IQR metabolic equivalent intensity minutes per week $1,104,136-$ $17,000)$ than in patients with osteoporosis $(720,0-2,520)$ or osteopenia $(560,25-3,548)(P=.24)$.

Table 4 shows the pulmonary function test results. The osteoporosis patients had lower absolute $\mathrm{FEV}_{1}, \mathrm{FVC}$, inspiratory capacity, and ratio of inspiratory capacity to total 
Table 4. Pulmonary Function Relative to Osteoporosis, Osteopenia, and Normal Bone Mass

\begin{tabular}{|c|c|c|c|c|}
\hline & $\begin{array}{l}\text { Osteoporosis } \\
\quad(n=40)\end{array}$ & $\begin{array}{l}\text { Osteopenia } \\
(n=40)\end{array}$ & $\begin{array}{l}\text { Normal Bone Mass } \\
\qquad(n=15)\end{array}$ & $P$ \\
\hline $\mathrm{FEV}_{1}(\mathrm{~L})$ & $0.98 \pm 0.36^{*}$ & $1.03 \pm 0.42$ & $1.30 \pm 0.56^{*}$ & .041 \\
\hline FVC (L) & $1.97 \pm 0.69 *$ & $2.26 \pm 0.67$ & $2.71 \pm 0.63 *$ & .002 \\
\hline FRC (\% predicted) & $194.1 \pm 54.3^{*}$ & $184.6 \pm 44.9$ & $151.6 \pm 47.6^{*}$ & .02 \\
\hline Inspiratory capacity (L) & $1.23 \pm 0.59^{*}$ & $1.32 \pm 0.58 \dagger$ & $1.78 \pm 0.57 * \dagger$ & .009 \\
\hline Inspiratory capacity/TLC & $0.19 \pm 0.08 *$ & $0.20 \pm 0.09$ & $0.26 \pm 0.07 *$ & .03 \\
\hline $\mathrm{D}_{\mathrm{LCO}}(\mathrm{mL} / \mathrm{min} / \mathrm{mm} \mathrm{Hg})$ & $9.73 \pm 4.43$ & $8.9 \pm 2.87 \dagger$ & $13.2 \pm 7.68 \dagger$ & .02 \\
\hline $\mathrm{D}_{\mathrm{LCO}}(\%$ predicted $)$ & $44.1 \pm 15.6$ & $38.7 \pm 11.9 \dagger$ & $53.9 \pm 23.9 \dagger$ & .01 \\
\hline Dyspnea score, median (IQR) $\ddagger$ & $3(2-4)$ & $3(2-4)$ & $1(1-4)$ & .21 \\
\hline 6-min walk distance (m) & $367.5 \pm 106.3$ & $385.8 \pm 118.3$ & $433.6 \pm 122.9$ & .19 \\
\hline BODE index, median (IQR) & $5(3-6)$ & $4(3-6)$ & $3(2-5)$ & .19 \\
\hline GOLD COPD stage, no. (\%) & & & & $.82 \S$ \\
\hline $\mathrm{I}: \mathrm{FEV}_{1} \geq 80 \%$ predicted & 0 & 0 & $1(7)$ & \\
\hline II: $\mathrm{FEV}_{1} 50-80 \%$ predicted & $10(25)$ & $8(20)$ & $3(20)$ & \\
\hline III: $\mathrm{FEV}_{1} 30-50 \%$ predicted & $21(53)$ & $18(45)$ & $7(47)$ & \\
\hline $\begin{array}{l}\text { IV: } \mathrm{FEV}_{1}<30 \% \text { predicted, or } \mathrm{FEV}_{1}<50 \% \\
\text { predicted plus chronic respiratory failure }\end{array}$ & $9(23) \|$ & $14(35)$ & $4(27) \|$ & \\
\hline \multicolumn{5}{|l|}{ \pm values are mean $\pm S D$} \\
\hline \multirow{2}{*}{\multicolumn{5}{|c|}{$\begin{array}{l}* P \text { for the comparison between osteoporosis and normal bone mass. } \\
\dagger P \text { for the comparison between osteopenia and normal bone mass. }\end{array}$}} \\
\hline \multirow{2}{*}{\multicolumn{5}{|c|}{$\begin{array}{l}\dagger P \text { for the comparison between osteopenia and normal bone mass. } \\
\ddagger \text { Dyspnea measured with the modified Medical Research Council dyspnea scale. }\end{array}$}} \\
\hline & & & & \\
\hline \multicolumn{5}{|c|}{$\S P$ for the comparison between stage I and II and stage III and IV. } \\
\hline \multirow{2}{*}{\multicolumn{5}{|c|}{$\begin{array}{l}\| \text { Values do not sum to } 100 \% \text { because of rounding. } \\
\text { FVC }=\text { forced vital capacity }\end{array}$}} \\
\hline \multirow{2}{*}{\multicolumn{5}{|c|}{$\begin{array}{l}\mathrm{FVC}=\text { forced vital capacity } \\
\text { FRC }=\text { functional residual capacity }\end{array}$}} \\
\hline & \multicolumn{3}{|c|}{ TLC $=$ total lung capacity } & \\
\hline \multirow{2}{*}{\multicolumn{5}{|c|}{$\begin{array}{l}\mathrm{D}_{\mathrm{LCO}}=\text { diffusing capacity of the lung for carbon monoxide } \\
\text { BODE = body-mass index, airflow obstruction, dyspnea, and exercise capacity }\end{array}$}} \\
\hline BODE $=$ body-mass index, airflow obstruction, dyspnea, and ex & & & & \\
\hline GOLD $=$ Global Initiative for Chronic Obstructive Lung Disease & & & & \\
\hline
\end{tabular}

lung capacity than the patients with normal bone mass. Inspiratory capacity was also lower in the patients with osteopenia than in the patients with normal bone mass. Percent-of-predicted functional residual capacity was higher in the patients with osteoporosis than in the patients with normal bone mass. The osteopenic patients had lower absolute and percent-of-predicted $\mathrm{D}_{\mathrm{LCO}}$ than those with normal bone mass; in patients with osteoporosis this difference was not statistically significant.

There was no significant difference between the osteoporotic, osteopenic, and normal-bone-mass patients in GOLD COPD stage. The BODE index was higher in the osteoporosis patients $(5,3-6)$ than the normal-bone-mass patients $(3,2-5)(P=.19)$, but this difference did not reach statistical significance.

With bivariate correlation we found significant positive correlations between femoral-neck T-score and BMI ( $\mathrm{r}=0.551, P<.001)$, and femoral-neck T-score and International Physical Activity Questionnaire total activity ( $\mathrm{r}=0.378, P<.001)$. There was a significant inverse relationship between femoral-neck T-score and BODE in$\operatorname{dex}(\mathrm{r}=-0.246, P=.02)$. We also found significant correlations between both femoral-neck T-score and lumbar-spine $\mathrm{T}$-score and $\mathrm{FEV}_{1}, \mathrm{FVC}$, percent-of-predicted functional residual capacity, inspiratory capacity, ratio of inspiratory capacity to total lung capacity, and absolute and percent-of-predicted $\mathrm{D}_{\mathrm{LCO}}$ (Table 5). There were no significant correlations between femoral-neck T-score or lumbar spine $\mathrm{T}$-score and corticosteroid dose or duration of treatment, smoking pack-years (even analyzed by sex), daily calcium intake, 6-min walk distance, or sun exposure in winter or summer months.

\section{Discussion}

We evaluated the prevalence of osteoporosis in COPD patients and found that $42 \%$ had osteoporosis and $42 \%$ had osteopenia. We found significant positive correlations between femoral-neck T-score and BMI, and femoral-neck T-score and International Physical Activity Questionnaire total activity. There was a significant inverse relationship between femoral-neck T-score and BODE index, and significant correlations between T-score (both femoral-neck and lumbar-spine) and pulmonary function test results.

Osteoporosis is a systemic effect of COPD, but the mechanisms by which osteoporosis develop are debated. Probably its pathogenesis is multifactorial, including progressive reduction in physical activity, low BMI, changes in 
Table 5. Bivariate Correlations With Femoral-Neck and Lumbar-Spine T-Scores

\begin{tabular}{|c|c|c|c|c|}
\hline & \multicolumn{4}{|c|}{ T-Score } \\
\hline & \multicolumn{2}{|c|}{ Femoral Neck } & \multicolumn{2}{|c|}{ Lumbar Spine } \\
\hline & $\mathrm{r}$ & $P$ & $\mathrm{r}$ & $P$ \\
\hline Body mass index & 0.551 & $<.001$ & 0.117 & .26 \\
\hline BODE index & -0.246 & .02 & -0.119 & .25 \\
\hline International Physical Activity Questionnaire total score & 0.378 & $<.001$ & 0.150 & .15 \\
\hline $\mathrm{FEV}_{1}$ & 0.251 & .01 & 0.251 & .01 \\
\hline FVC & 0.229 & .03 & 0.404 & $<.001$ \\
\hline Percent-of-predicted FRC & -0.415 & $<.001$ & -0.203 & .05 \\
\hline $\mathrm{D}_{\mathrm{LCO}}$ & 0.366 & $<.001$ & 0.243 & .05 \\
\hline Percent-of-predicted $\mathrm{D}_{\mathrm{LCO}}$ & 0.338 & .003 & 0.193 & .10 \\
\hline Inspiratory capacity & 0.252 & .01 & 0.295 & .004 \\
\hline Inspiratory capacity/TLC & 0.241 & .02 & 0.204 & .049 \\
\hline Inhaled corticosteroid dose & 0.031 & .81 & 0.083 & .52 \\
\hline Inhaled corticosteroid duration of use & 0.225 & .09 & 0.289 & .056 \\
\hline Oral corticosteroid dose & -0.068 & .77 & -0.066 & .78 \\
\hline Oral corticosteroid duration of use & 0.081 & .73 & 0.020 & .93 \\
\hline Smoking pack-years & 0.199 & .06 & 0.146 & .17 \\
\hline Daily calcium intake & 0.015 & .90 & 0.162 & .17 \\
\hline 6-min walk distance & 0.091 & .40 & 0.190 & .08 \\
\hline Duration of sun exposure (winter) & 0.161 & .30 & -0.114 & .46 \\
\hline Duration of sun exposure (summer) & -0.045 & .81 & -0.274 & .14 \\
\hline \multicolumn{5}{|l|}{$\begin{array}{l}\text { BODE = body-mass index, airflow obstruction, dyspnea, and exercise capacity } \\
\text { FVC }=\text { forced vital capacity } \\
\text { FRC }=\text { functional residual capacity } \\
\text { D }_{\text {LCO }}=\text { diffusing capacity of the lung for carbon monoxide } \\
\text { TLC = total lung capacity }\end{array}$} \\
\hline
\end{tabular}

body composition, pharmacologic treatments, systemic inflammation, and hypogonadism. ${ }^{29}$ In a recent systematic review, ${ }^{30}$ the overall mean prevalence of osteoporosis in COPD patients was $35 \%$ (similar to our findings), and the correlates of osteoporosis were mainly measures of body composition, disease severity and use of corticosteroids.

Low BMI is a risk factor for osteoporosis. ${ }^{6,11} \mathrm{We}$ found that BMI was positively correlated with femoral-neck Tscore. Several studies support the relationship between bone mineral density and BMI. ${ }^{8,9}$ We did not find a relationship between low BMI and osteoporosis, probably because we had only 15 patients with a BMI $<21 \mathrm{~kg} / \mathrm{m}^{2}$. Nevertheless, osteoporosis was less common than normal bone mineral density or osteopenia among the overweight patients. In another cross-sectional study, overweight and obesity showed a substantial protective effect in osteoporosis. ${ }^{31}$

We found no correlation between bone mineral density and smoking-pack-years, in accordance with a previous investigation. ${ }^{27}$ However, smoking has long been recognized as an independent risk factor for osteoporosis. ${ }^{32,33}$ The mechanism of that association remains unsatisfactorily understood, but the effect appears to be dose-dependent. ${ }^{34}$ The fact that we did not find a correlation between smoking habits and bone mineral density might be attributable to our study design. Also, in specific populations a genetic component could play a role in the effects of smoking on bone mineral density.

Another modifiable risk factor associated with bone mineral density is physical inactivity. Previous studies ${ }^{35,36}$ found an inverse relationship between hip fracture and activity level. With the International Physical Activity Questionnaire (an instrument recommended by the World Health Organization for cross-national physical activity monitoring) we found a moderate correlation between the physical activity total score and femoral-neck bone mineral density, suggesting that physical inactivity could have a role in osteoporosis in those patients. Nevertheless, we did not find a significant correlation between 6-min walk distance and bone mineral density.

Surprisingly, we found that our white patients were less likely to have osteoporosis than our non-white patients. Racial differences in bone density are well described, and osteoporosis is more prevalent in white patients. ${ }^{37}$ Previous work found that ethnicity contributes to differences in fracture rates, even when bone density is similar. ${ }^{38}$ The role of ethnicity in osteoporosis and fractures is a subject of considerable controversy, especially in COPD patients. 


\section{Osteoporosis Prevalence and Associated Factors in Patients With COPD}

In a study of patients with severe COPD, ${ }^{39}$ osteoporosis was equally prevalent in African Americans and whites, suggesting that osteoporosis should be considered in COPD patients regardless of race.

Oral corticosteroids are also associated with osteoporosis. ${ }^{40}$ Controversy still exists on the role of inhaled corticosteroids in bone loss, although some studies have found that inhaled corticosteroids can also be associated with many of the adverse effects of oral corticosteroids, including osteoporosis. ${ }^{41,42}$ Previous studies ${ }^{27,31}$ found no significant influence of corticosteroids on osteoporosis, but they did not take into account the dose and duration of corticosteroid treatment. We considered these covariates but found no association between oral or inhaled corticosteroids and osteoporosis. First, corticosteroid use does not fully account for the low bone mineral density seen in COPD patients. ${ }^{43}$ Second, the increased risk of osteoporosis may be more related to the COPD severity than to the use of inhaled corticosteroids. ${ }^{44}$ Third, our patients had not been using high doses of inhaled corticosteroids, which are more frequently associated with low bone mineral density.

Regarding COPD severity, the patients with osteoporosis had worse lung function than the patients with normal bone mass. There was also a statistically significant, although weak, correlation between BODE index and bone mineral density. Actually, the risk of osteoporosis in COPD patients seems to be higher in severe COPD, as demonstrated previously. ${ }^{40}$ Impaired lung function can cause reduced physical activity and decreased sun exposure, which could be the factors associated with reduced bone mineral density. A higher corticosteroid treatment exposure is usually found in patients with a lower $\mathrm{FEV}_{1}$, which could partly explain a lower bone mineral density, although we did not find a significant correlation between these variables. In addition, severe COPD is associated with increased inflammatory markers, which are risk factors for osteoporosis. ${ }^{45}$

Vitamin D deficiency is extremely common in the elderly and is associated with increased risk of osteoporosis and fractures. Lack of sun exposure is widely accepted as the primary cause of epidemic low vitamin D. ${ }^{46}$ In our study, sun exposure and calcium intake were not related to bone mineral density. We used a sunlight-exposure questionnaire, but a recent review showed that these questionnaires can provide imprecise estimates of vitamin D status. ${ }^{47}$ We did not measure vitamin D blood level, which might reveal an association with bone mineral density.

\section{Limitations}

First, our cross-sectional study design does not allow definite determination of causal associations. Second, this was a single-center study with a small sample size. Third, some of the subjects may have incorrectly reported their sun exposure and/or physical activity level. Despite these limitations, our results were consistent with what we expected, based on the literature. Indeed, this study provides further evidence on correlates of osteoporosis. Based on the high prevalence of osteoporosis in our study, it seems reasonable to conclude that patients with COPD, irrespective of disease severity, should routinely have their bone mineral density evaluated.

\section{Conclusions}

We identified a high prevalence of osteoporosis and osteopenia in out-patients with COPD. The patients with osteoporosis had more severe COPD than the patients with normal bone mass. In addition, we found significant correlations between bone mineral density and BMI, physical activity, and BODE index. We did not find an association between bone mineral density and sun exposure, corticosteroid treatment, or smoking pack-years.

\section{REFERENCES}

1. Barnes PJ. Chronic obstructive pulmonary disease. N Engl J Med 2000;343(4):269-278.

2. Stone AC, Nici L. Other systemic manifestations of chronic obstructive pulmonary disease. Clin Chest Med 2007;28(3):553-555.

3. Barnes PJ, Celli BR. Systemic manifestations and comorbidities of COPD. Eur Respir J 2009;33(5):1165-1185.

4. World Health organization (WHO). Prevention and management of osteoporosis: report of a WHO scientific group. http://whqlibdoc. who.int/trs/WHO_TRS_921.pdf. Accessed May 10, 2011.

5. Sabit R, Bolton CE, Edwards PH, Pettit RJ, Evans WD, McEniery $\mathrm{CM}$, et al. Arterial stiffness and osteoporosis in chronic obstructive pulmonary disease. Am J Respir Crit Care Med 2007;175(12):12591265.

6. Bolton CE, Ionescu AA, Shiels KM, Pettit RJ, Edwards PH, Stone $\mathrm{MD}$, et al. Associated loss of fat-free mass and bone mineral density in chronic obstructive pulmonary disease. Am J Respir Crit Care Med 2004;170(12):1286-1293.

7. Shane E, Silverberg SJ, Donovan D, Papadopoulos A, Staron RB, Addesso $\mathrm{V}$, et al. Osteoporosis in lung transplantation candidates with end-stage pulmonary disease. Am J Med 1996;101(3):262-269.

8. Incalzi RA, Caradonna P, Ranieri P, Basso S, Fuso L, Pagano F, et al. Correlates of osteoporosis in chronic obstructive pulmonary disease. Respir Med 2000;94(11):1079-1084.

9. Iqbal F, Michaelson J, Thaler L, Rubin J, Roman J, Nanes MS. Declining bone mass in men with chronic pulmonary disease: contribution of glucocorticoid treatment, body mass index, and gonadal function. Chest 1999;116(6):1616-1624.

10. Kjensli A, Mowinckel P, Ryg MS. Low bone mineral density is related to severity of chronic obstructive pulmonary disease. Bone 2007;40(2):493-497.

11. Vrieze A, de Greef MH, Wykstra PJ. Low bone mineral density in COPD patients related to worse lung function, low weight and decreased fat-free mass. Osteopor Int 2007;18(9):1197-1202.

12. Rabe KF, Hurd S, Anzueto A, Barnes PJ, Buist SA, Calverley P, et al. Global strategy for the diagnosis, management, and prevention of chronic obstructive pulmonary. GOLD executive summary. Am J Respir Crit Care Med 2007;176(6):532-555. 


\section{Osteoporosis Prevalence and Associated Factors in Patients With COPD}

13. Laranjeira R, Pinsky I. O alcoolismo. In: Laranjeira R, Pinsky I, editors. O alcoolismo. Mitos e verdades. São Paulo, Brazil: Contexto; 2000;1. Book in Portugese.

14. World Health Organization. Assessment of fracture risk and its application to screening for postmenopausal osteoporosis: report of a WHO study group. http://whqlibdoc.who.int/trs/WHO_TRS_843.pdf. Accessed May 10, 2011.

15. Miller MR, Hankinson J, Brusasco V, Burgos F, Casaburi R, Coates A, et al. Standardization on spirometry. Eur Respir J 2005;26(2): 319-338.

16. Wanger J, Clausen JL, Coates A, Pedersen OF, Brusasco V, Burgos $\mathrm{F}$, et al. Standardization of measurement of lung volumes. Eur Respir J 2005;26(3):511-522.

17. Macintyre N, Crapo RO, Viegi G, Johnson DC, van der Grinten CP, Brusasco V, et al. Standardization of the single-breath determination of carbon monoxide uptake in the lung. Eur Respir J 2005;26(4):720-735.

18. Crapo RO, Morris AH, Gardner RM. Reference spirometric values using techniques and equipment that meet ATS recommendations. Am Rev Respir Dis 1981;123(6):659-664.

19. Crapo RO, Morris AH, Clayton PD, Nixon CR. Lung volumes in healthy non-smoking adults. Bulletin European de Physiopathologie Respiratoire 1982;18(3):419-425.

20. Crapo RO, Morris AH. Standardized single breath normal values for carbon monoxide diffusion capacity. Am Rev Respir Dis 1981;123(2): 185-189.

21. Mahler D, Wells C. Evaluation of clinical methods of rating dyspnea. Chest 1988;93(3):580-586.

22. Celli BR, Cote CG, Marin JM, Casanova C, Montes de Oca M, Mendez RA, et al. The body-mass index, airflow obstruction, dyspnea, and exercise capacity index in chronic obstructive pulmonary disease. N Engl J Med 2004;350(10):1005-1012.

23. Hu FB, Rimm E, Smith-Warner SA, Feskanich D, Stampfer MJ, Ascherio A, et al. Reproducibility and validity of dietary patterns assessed with a food-frequency questionnaire. Am J Clin Nutr 1999; 69(2):243-249.

24. Rimm EB, Giovannucci EL, Stampfer MJ, Colditz GA, Litin LB, Willett WC. Reproducibility and validity of an expanded selfadministered semiquantitative food frequency questionnaire among male health professionals. Am J Epidemiol 1992;135(10): 1114-1126.

25. Ainsworth BE, Haskell WL, Whitt MC, Irwin ML, Swartz AM, Strath SJ, et al. Compendium of physical activities: an update of activity codes and MET intensities. Med Sci Sports Exerc 2000;32(9 Suppl):S498-S504.

26. Fitzpatrick TB. Soleil et peau. J Med Esthet 1975;3(1):33-34. Article in French.

27. Jorgensen NR, Schwarz P, Holme I, Henriksen BM, Petersen LJ, Backer V. The prevalence of osteoporosis in patients with chronic obstructive pulmonary disease: a cross sectional study. Respir Med 2007;101(1):177-185.

28. Vries F, Staa TP, Bracke MSGM, Cooper C, Leufkens HGM, Lammers JWJ. Severity of obstructive airway disease and risk of osteoporotic fracture. Eur Respir J 2005;25(5):879-884.

29. Ionescu AA, Schoon E. Osteoporosis in chronic obstructive pulmonary disease. Eur Respir J 2003;22(Suppl 46):64S-75S.
30. Graat-Verboom L, Wouters EF, Smeenk FW, van den Borne BE, Lunde R, Spruit MA. Current status of research on osteoporosis in COPD: a systematic review. Eur Respir J 2009;34(1):209-218.

31. Graat-Verboom L, Spruit MA, van den Borne BE, Smeenk FW, Martens EJ, Lunde R, Wouters EF; CIRO Network. Correlates of osteoporosis in chronic obstructive pulmonary disease: an underestimated systemic component. Respir Med 2009;103(8):11431151.

32. Kiel DP, Zhang Y, Hannan MT, Anderson JJ, Baron JA, Felson DT. The effect of smoking at different life stages on bone mineral density in elderly men and women. Osteoporos Int 1996;6(3):240248 .

33. Law MR, Hackshaw AK. A meta-analysis of cigarette smoking, bone mineral density and risk of hip fracture: recognition of a major effect. BMJ 1997;315(7112):841-846.

34. Wong PKK, Christie JJ, Wark JD. The effects of smoking on bone health. Clin Sci 2007;113(5):233-241.

35. Cooper C, Barker DJ, Wickham C. Physical activity, muscle strength, and calcium intake in fracture of the proximal femur in Britain. BMJ 1988;297(6661):1443-1446.

36. Cummings SR, Nevitt MC, Browner WS, Stone K, Fox KM, Ensrud $\mathrm{KE}$, et al. Risk factors for hip fracture in white women. N Engl J Med 1995;332(12):767-773.

37. Looker AC, Wahner HW, Dunn WL, Calvo MS, Harris TB, Heyse SP, et al. Updated data on proximal femur bone mineral levels of US adults. Osteoporos Int 1998;8(5):468-489.

38. Barrett-Connor E, Siris ES, Wehren LE, Miller PD, Abbott TA, Berger ML, et al. Osteoporosis and fracture risk in women of different ethnic groups. J Bone Miner Res 2005;20(2):185-194.

39. Li L, Brennan KJ, Gaughan JP, Ciccolella DE, Kuzma AM, Criner GJ. African-Americans and men with severe COPD have a high prevalence of osteoporosis. COPD 2008;5(5):291-297.

40. Maggi S, Siviero P, Gonnelli S, Schiraldi C, Malavolta N, Nuti R, Crepaldi G. Osteoporosis risk in patients with chronic obstructive pulmonary disease: The EOLO study. J Clin Densitom 2009;12(3):345-352.

41. Goldstein JL, Fallon JJ Jr, Harning R. Chronic glucocorticoid therapy-induced osteoporosis in patients with obstructive lung disease. Chest 1999;116(6):1733-1749.

42. Ip M, Lam K, Yam L. Decreased bone mineral density in premenopausal asthma patients receiving long-term inhaled steroids Chest 1994;105(6):1722-1727.

43. Biskobing DM. COPD and osteoporosis. Chest 2002;121(2):609620.

44. Jones A, Fay JK, Burr M, Stone M, Hood K, Roberts G. Inhaled corticosteroid effects on bone metabolism in asthma and mild chronic obstructive pulmonary disease. Cochrane Database Syst Rev;2002(1): CD003537.

45. Gan WQ, Man SF, Senthilselvan A, Sin DD. Association between chronic obstructive pulmonary disease and systemic inflammation: a systematic review and a meta-analysis. Thorax 2004;59(7): 574-580.

46. Holick MF. Sunlight and vitamin D for bone health and prevention of autoimmune diseases, cancers, and cardiovascular disease. Am J Clin Nutr 2004;80(6 Suppl):1678S-1688S.

47. McCarty CA. Sunlight exposure assessment: can we accurately assess vitamin D exposure from sunlight questionnaires? Am J Clin Nutr 2008;87(4):1097S-1101S. 